\title{
NEW ALKYL PHENOLS AND FATTY ACID PROFILE FROM OILS OF PULPED Spondias mombin L. SEED WASTES
}

\author{
Larissa C. de Rezende ${ }^{a, c}$, Patricia de A. Santos ${ }^{a}$, Valéria B. Riatto ${ }^{\mathrm{a}}$, Jorge M. David ${ }^{\mathrm{a}, *}$ and Juceni P. David $^{\mathrm{b}}$ \\ anstituto de Química, Universidade Federal da Bahia, 40170-290 Salvador - BA, Brasil \\ ${ }^{b}$ Faculdade de Farmácia, Universidade Federal da Bahia, 40170-290 Salvador - BA, Brasil \\ 'Departamento de Ciências Exatas e Naturais, Universidade Estadual do Sudoeste da Bahia, Praça Primavera, 40, 45700-000 \\ Itapetinga - BA, Brasil
}

Recebido em 16/12/2017; aceito em 01/02/2018; publicado na web em 22/02/2018

\begin{abstract}
Spondias mombin L. is a Brazilian tree belonging to the family Anacardiaceae and popularly known as "cajá", the genus is well known by the various exotic fruit species such as "siriguela" (S. purpurea), "umbu" (S. tuberosa) and "umbu-cajâ" (S. bahiensis). It presents commercial importance to the locals especially due the small juice fruit industries and the seeds are often discarded as waste after pulping. Despite the regional importance, even today there is little information on the chemical composition of these fruits. Thus, the dichloromethane extract of the waste seeds of S. mombin was subjected to different chromatographic fractionation allowing the isolation of a main triglyceride identified as 1,3-dioleoyl-2-linoleoyl glycerol, two new alkyl phenols named 1-hydroxyl-3-[(Z)-10'octadecenyl]-benzene and 1-hydroxyl-3-[(Z)-10'-docosenyl] benzene, and a mixture of phytosteroids. The seed's fatty acid profile and the cytotoxicity of the oils and isolated compounds were also determinated employing BST. The alkenylphenol mixture present some toxicity $\left(\mathrm{CL}_{50} 215,4 \mu \mathrm{g} \mathrm{mL} \mathrm{m}^{-1}\right)$ in this test.
\end{abstract}

Keywords: Spondias mombin; 1-hydroxy-3-[(Z)-10'-docosenyl] benzene; 1-hydroxyl-3-[(Z)-10'-octadecenyl]-benzene; fatty acids.

\section{INTRODUTION}

Presently in Brazil the fruit production is based on the demand for fresh fruits because of its nutritional value and commercial values, especially for export. Besides, it is increasing the demand for tropical fruits due their unique and exotic flavor. The industrial processing of tropical and subtropical fruits generates relatively high amounts of waste such as bagasse, bark and seeds, which are often dropped and that could be used to reduce food waste. Brazilian fruit industries produce waste that could have a much more beneficial purpose to man and the environment. ${ }^{1}$

Fruit seeds are considered important sources of oil presenting nutritional, industrial and pharmaceutical relevance. The use of the oil of the fruit seeds could be an alternative in the use of agroindustrial waste. These residues of fruit seeds are also considerable besides others, source of energy in the biodiesel production from the extracted vegetable oils. ${ }^{2}$

The genus Spondias (Anacardiaceae) comprehends tropical trees mostly of them producing edible fruits that present economic potential to the local Brazilian farmers. The exploitation of fruits of species of this genus basically involves family labor and, the fruits are sold in local markets and used to prepare juices, sweets, ice cream, coolers and liquors, as well gum extraction. Spondias mombin L. is popularly known as "cajá", it is a native tree mainly found in the north and northeast brazilian regions. ${ }^{3}$ In these regions are also common finding other Spondias spp. such as "siriguela" $(S$. purpurea), "umbu" (Spondias tuberosa), "cajarana" (S. cytherea) and "umbu-caja" (S. bahiensis). ${ }^{4}$

Native $S$. mombin fruits present potential use for food processing to produce jelly, juice, jams and ice cream mainly in northeastern Brazil. Besides, the leaves are used in folk medicine in the treatment of several topic and systemic diseases such as mouth and throat's inflammations, in cases of prostatitis and herpes labialis. A survey

*e-mail: jmdavid@ufba.br of the relevant literature revealed $S$. mombin exhibit antimicrobial, leishmanicide, antiviral, hypoglycemic and antioxidant activities. ${ }^{5}$

To date, there are few studies dealing with chemical composition and biological activities of $S$. mombin extracts. Antiviral ellagitannins and caffeoyl esters besides alkenyl salicylic acids were isolated from the leaves and stems of this plant. ${ }^{6}$ However, the chemical composition of these fruits is almost unknown, Hamano and Mercadante ${ }^{7}$ determined by HPLC the carotenoid composition and vitamin A values of Brazilian commercial products of "cajá" fruits, frozen pulps and pasteurized juices. The ripe fruit of $S$. mombin is an approximately $3.8 \mathrm{~cm}$ long oval yellow plum with a thin, smooth and yellow skin, edible pulp with a very exotic taste. Very rich in vitamins $\mathrm{B}_{1}$ and $\mathrm{C}$, the fruit mostly exists as a single and oval seed measuring $2.5 \times 1.5 \mathrm{~cm}^{8}$

Currently, pulp industries of tropical fruit existing in Bahia State (Brazil) very often discard the peels and seeds after the process of cutting and fruit juice extractions. As this disposal represents many tons by year; so, a way for adding value to these by-products presents economic, scientific and technological interest. The $S$. mombin oil seeds must have its chemical composition determined for use in feed or even for biodiesel. In addition, the oil should not be toxic. In this work, we carried out a study to characterize the chemical composition and toxicity of hog plum seeds' oil, aiming at an employment for the local industrial waste seeds.

\section{EXPERIMENTAL}

\section{General procedures}

All solvents employed were analytical-grade from Qhemis ${ }^{\circledR}$ and Baker $^{\circledR}$, dimethyl disulfide and F.A.M.E. (fatty acid methyl esters) mixture used were purchased from Sigma-Aldrich, sodium methoxide from Fluka and resublimed iodine and sodium thiosulfate were obtained from Merck. Silica gel 60 (63-200 and 40-63 $\mu \mathrm{m})$ from Acros were employed in the column chromatographic separations 
and, precoated Silica gel $60 \mathrm{~F}_{254}$ TLC plates (Merck) were used to monitoring the chromatographic fractions revealed by iodine fumes and/or UV light (254/365 nm).

The NMR spectra (mono and bidimensional) were obtained on a Varian equipment mod. Gemini 2000 operating at $300 \mathrm{MHz}$ $\left({ }^{1} \mathrm{H}\right)$ and $75 \mathrm{MHz}\left({ }^{13} \mathrm{C}\right)$ and on a Bruker mod. AC250 operating at $250 \mathrm{MHz}\left({ }^{1} \mathrm{H}\right)$, employing $\mathrm{CDCl}_{3}\left(\right.$ Aldrich $\left.^{\circledR}\right)$ as solvent and TMS as the internal standard. FTIR spectra were recorded in a Shimiadzu spectrophotomer mod. IRAfinnity.

The fatty acid methyl esters were analyzed on a Shimadzu GC-MS equipment (mod. QP2010) using a $30.0 \mathrm{~m}$ x $0.25 \mathrm{~mm}$ Rtx-1MS column (Crossbond $100 \%$ dimethyl polysiloxane) with $0.25 \mu \mathrm{m}$ film. The operating conditions of the chromatographic analysis were as follows: temperature of the column started at $100{ }^{\circ} \mathrm{C}$ with heating rate $5^{\circ} \mathrm{C} \mathrm{min}^{-1}$ to $200^{\circ} \mathrm{C}$ and then it was increased to $280^{\circ} \mathrm{C}$ at $10^{\circ} \mathrm{C} \mathrm{min}^{-1}$; injector was set at $250{ }^{\circ} \mathrm{C}$; interface temperature of $280^{\circ} \mathrm{C}$; ion-source temperature of $250^{\circ} \mathrm{C}$ and helium was used as carrier gas (flow rate $18 \mathrm{~mL} \mathrm{~min}^{-1}$ ). Mass spectra were recorded in mass spectrometer operating in scan form; the filament voltage of $70 \mathrm{eV}$; detector voltage $1.3 \mathrm{KV}$ and quadrupole analyzer. The methyl esters were identified by comparison to the mass spectra in NIST 147 e WILEY 8 libraries and F.A.M.E (fatty acid methyl esters) mixture as standard.

\section{Extraction and isolation of chemical constituents}

Spondias mombin hog plum were purchased in street markets of the city of Salvador, they were pulped, and the obtained seeds dried and crushed obtaining $172.38 \mathrm{~g}$. The voucher was deposited in the Herbarium of the Universidade Federal da Bahia with number of identification JMD-51. The dried and pulverized material was subjected to three consecutive extractions with ethanol $(300 \mathrm{~mL})$ for 48 hours, followed by concentration under reduced pressure. The ethanol extract obtained was dissolved in $\mathrm{MeOH}: \mathrm{H}_{2} \mathrm{O}$ (7:3) and then partitioned between $\mathrm{CH}_{2} \mathrm{Cl}_{2}: \mathrm{MeOH} / \mathrm{H}_{2} \mathrm{O}$ and after removal of solvent yielding $4.49 \mathrm{~g}$ of $\mathrm{CH}_{2} \mathrm{Cl}_{2}$ soluble fraction. The $\mathrm{CH}_{2} \mathrm{Cl}_{2}$ extract was submitted to a $\mathrm{CC}$ over silica gel 60 and eluted with a gradient of hexane:EtOAc mixtures, the similar fractions were grouped by TLC analysis employing UV light as the revelator $(254 / 366 \mathrm{~nm})$.

The fractions from the main CC eluted with a hexane:EtOAc (9:1 and $8: 2$ ) allowed to obtain $2 \mathrm{~g}$ of triglyceride. The fractions eluted with $30 \%$ EtOAc $(83.0 \mathrm{mg})$ from the main CC was submitted to CC using hexane:EtOAc (9:1) furnishing a mixture of $n$-alkyl phenols $(12.3 \mathrm{mg})$. The fractions eluted with 50\% EtOAc (232 mg) afforded the mixture of $\beta$-sitosterol and stigmasterol (79.6 mg).

1-Hydroxyl-3-[(Z)-10'-octadecenyl]-benzene (2) and 1-hydroxyl3-[(Z)-10'-docosenyl] benzene (3). Oil. Negative HRMS [M-H]' $\mathrm{m} / \mathrm{z}$ 343.3012 (2) and $399.3632(3)\left[\mathrm{C}_{24} \mathrm{H}_{40} \mathrm{O}\right.$ and $\mathrm{C}_{28} \mathrm{H}_{48} \mathrm{O}$ requires 343.3000 and 399.3627]. IR (film) $v_{\max } 3420-3200(\mathrm{OH}), 2930$ (C$\mathrm{H}), 2849(\mathrm{C}-\mathrm{H}), 1610$ (C=C), $1272(\mathrm{C}-\mathrm{O}) ;{ }^{1} \mathrm{H} \mathrm{NMR}$ and ${ }^{13} \mathrm{C} \mathrm{NMR}$ data, see Table 2.

\section{Transesterification reaction}

The methyl esters were obtained from the reflux of $25 \mathrm{mg}$ of triglyceride with sodium methoxide solution $\left(0.5 \mathrm{~mol} \mathrm{~L}^{-1}\right)$ in methanol $(2.0 \mathrm{~mL})$. The isolation of the methyl esters was performed after adding distilled water to the reaction mixture, followed by extraction with hexane and DCM.

\section{Thioalkylation reaction}

The alkenyl phenols $(3.0 \mathrm{mg})$ were subjected to an addition reaction employing $1 \mathrm{~mL}$ dimethyl disulfide and iodine as catalyst $\left(6 \mathrm{mg} \mathrm{mL}^{-1}\right)$. The system was purged with nitrogen and kept closed under magnetic stirring for $24-48 \mathrm{~h}$ at room temperature, followed by treating in the system with $1 \mathrm{~mL}$ of an aqueous sodium thiosulfate $(5 \%)$ solution. Subsequently the mixture was separated into binary separatory funnel, and the solvent was eliminated at reduced pressure in a rotary evaporator. ${ }^{9}$

\section{Brine Shrimp test}

The brine shrimp lethality assay was performed using methodology previously described with minor modifications. ${ }^{10}$ Brine shrimp (Artemia salina) eggs were hatched in artificial seawater and the extracts, fractions and isolated compounds were tested at concentrations of 50, 75, 100, 150, 300, 600 and $1000 \mu \mathrm{g} \mathrm{mL}^{-1}$. After 24 hours of incubation with the tested samples at $25^{\circ} \mathrm{C}$, the number of nauplii that remained alive were evaluated. Artificial seawater was employed as a negative control (blank) and podophyllotoxin as a positive control. The data analyzed and $\mathrm{LC}_{50}$ values were determined by Probit analysis with a $95 \%$ confidence interval.

\section{RESULTS AND DISCUSSION}

From the DCM soluble fraction obtained from the seeds of $S$. mombin were isolated by chromatographic techniques the triglyceride $\mathbf{1}$, the mixture of new alkenyl phenols $\mathbf{2}$ and $\mathbf{3}$, as well as a 3:1 mixture of $\beta$-sitosterol (4) and stigmasterol (5) determinated by NMR analysis (Figure 1).

The fraction eluted with from the main silica gel $\mathrm{CC}$ was enriched with one specific triglyceride. This finding was based on the mass spectra and NMR spectroscopy such as ${ }^{1} \mathrm{H}$ and detailed ${ }^{13} \mathrm{C}$ NMR data analysis (including DEPT experiment). Detailed analysis of the ${ }^{1} \mathrm{H}$ NMR spectrum revealed that this triglyceride was a mixture of fatty acids due to the presence of the triplet at $\delta 0.89$ attributed to methyl hydrogens; a peak at $\delta 1.23$ due to methylene group hydrogens ( $\beta$-olefinic and/or $\gamma$-carbonyl); peak at $\delta 1.62$ attributed to methylene $\beta$-carbonyl hydrogens; peak at $\delta 2.05$ of allylic hydrogens; $\alpha$-carbonyl hydrogens at $\delta 2.32$; bis-allylic hydrogens at $\delta 2.77$; multiplet of olefin ( $\delta 5.35$ ); oxymethylene hydrogens triplets at $\delta 4.23$ due the peaks of C-1 and C-3 hydrogens the glycerol moiety and the C-2 hydrogen at $\delta 5.26 .{ }^{11}$ Comparison of the spectra of ${ }^{1} \mathrm{H}$ NMR of the main triglyceride present in the seed oil of $S$. mombin and sunflower, olive and corn oil spectra profile, it appears that have similarity with the main triglycerides from sunflower and corn oils. ${ }^{12}$

The ${ }^{13} \mathrm{C}$ NMR spectrum data together with the experiment DEPT $135^{\circ}$ experiment showed signals for acyl carbons at $\delta 173.2$ and 172.8; olefinic carbons at $\delta 130.2,129.9,129.7$ and 128.1, 127.9, indicating the presence of two unsaturated fatty acids besides the resonances of $\mathrm{C} 1$ and $\mathrm{C} 2$ carbon of the glycerol $(\delta 68.9$ and 62.1) moiety. Chemical shifts displayed at $\delta 34.2$ and 34.0 correspond to $\alpha$-methylene groups in relation to the carboxyl; saturated $\mathrm{CH}_{2}$ groups are at $\delta 31.9$ to 22.5; $\mathrm{CH}_{2}$ external allylic to the olefinic double bond, presented a peak at $\delta 27.2 ; \mathrm{CH}_{2}$ internal olefin was observed at $\delta 25.6$; the $\beta$-carbonyl carbons were observed at $\delta 24.9$ and methyl groups were observed at $\delta 14.0$ and $14.1 .^{13}$ Thus, through the analysis of these findings and employing the methodology for triglyceride identification ${ }^{14}$ was possible to proposed the main triglyceride present in the seed's oil was a mixed ABA triacylglycerol named glycerol 1,3-dioleoyl-2-linoleoyl (OLO). To corroborate with this proposal, after derivatization of triglycerides from the seed oil by transesterification reaction and obtaining the corresponding methyl esters, they were identified by GC/MS and by F.A.M.E. standard. In the chromatogram was recorded five majority peaks with different retention times, and each gave a 
mass spectrum whose respective molecular ions at $\mathrm{m} / \mathrm{z}, 270, \mathrm{~m} / \mathrm{z}, 294$, $\mathrm{m} / \mathrm{z}, 296, \mathrm{~m} / \mathrm{z}, 298$ and $\mathrm{m} / \mathrm{z}, 466$ are fragments corresponding to methyl esters of palmitic (hexadecanoic), linoleic (9,12-octadecadienoic), oleic (9-octadecenoic), stearic (octadecanoic) and melissic (triacontanoic) acids (Table 1). The analyzes corroborate the oil is composed majority by unsaturated fatty acids.

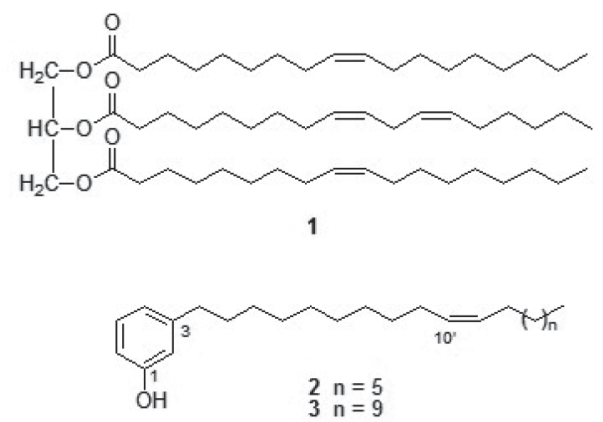

Figure 1. Isolated compounds from the seed oil of Spondias mombin

Table 1. Fatty acid composition of triglyceride of the seed oil of S. mombin Fatty acid $\% \pm$ SD

\begin{tabular}{lc}
\hline Palmitic, C16:0 & $25.795 \pm 1.520$ \\
Linoleic, C18:2 & $31.660 \pm 0.580$ \\
Oleic, C18:1 & $24.415 \pm 1.407$ \\
Stearic, C18:0 & $13.870 \pm 0.226$ \\
Melissic, C30:0 & $4.255 \pm 0.460$ \\
Unsaturated fatty acids & 56.08 \\
Saturated fatty acid & 43.92 \\
Total identified & 100 \\
\hline
\end{tabular}

SD: standard deviation.

The structural determination of the inseparable mixture of new alkenyl phenols $\mathbf{2}$ and $\mathbf{3}$ was established through analysis of data obtained from NMR and MS data. The negative HRESIMS showed pseudo-molecular ions [M-H] at $m / z, 343.3012$ and 399.3632. These data combined with data ${ }^{1} \mathrm{H}$ NMR and ${ }^{13} \mathrm{C}$ (including DEPT) allowed to propose the molecular formula $\mathrm{C}_{24} \mathrm{H}_{40} \mathrm{O}$ and $\mathrm{C}_{28} \mathrm{H}_{48} \mathrm{O}$ for compounds $\mathbf{2}$ and $\mathbf{3}$, respectively. The ${ }^{1} \mathrm{H}$ NMR spectrum showed signals in the aromatic region whose integration corresponded to four hydrogens, suggesting the presence of disubstituted aromatic ring. However, the observed peak multiplicities cannot clarify the pattern of ring substitution. The peak at $\delta 5.35(t, \mathrm{~J}=4.7 \mathrm{~Hz})$, integrating for two hydrogens, was attributed of similar olefinic hydrogens and the C-12' and C-9' methylene resonances ( $\delta 27.2$ and 26.9) in the ${ }^{13} \mathrm{C}$ NMR spectra are indicative of $Z$ disubstituted double bond. ${ }^{15}$ These data together with the signals from $\delta 0.90$ to 2.50 hydrogens suggested the presence of alkenylic chain bonded a disubstituted aromatic ring. The bidimensional experiments (HMQC and HMBC) contributed to assign the phenyl groups present in the structure but they did not help in the unequivocal structural elucidation. The corrected phenyl pattern substitution was suggested by ${ }^{13} \mathrm{C}$ NMR data comparison with those described in the literature and prediction chemical shift
Table 2. $\mathrm{NMR}{ }^{13} \mathrm{C}\left[75 \mathrm{MHz}, \mathrm{CDCl}_{3}\right]$ and ${ }^{1} \mathrm{H}\left[300 \mathrm{MHz}, \mathrm{CDCl}_{3}\right.$ data of alkenyl phenols $\mathbf{2}$ and $\mathbf{3}$

\begin{tabular}{|c|c|c|}
\hline $\mathrm{H} / \mathrm{C}$ & $\begin{array}{c}\delta{ }^{1} \mathrm{H} \\
{[(\text { multiplicity, } J(\mathrm{~Hz})]}\end{array}$ & $\delta^{13} \mathrm{C}$ \\
\hline 1 & - & 155.4 \\
\hline 2 & $6.63-6.66 \mathrm{~m}$ & 115.3 \\
\hline 3 & - & 144.9 \\
\hline 4 & $6.75 \mathrm{~d}(J=7.7)$ & 120.9 \\
\hline 5 & $7.13 \mathrm{t}(J=7.7)$ & 129.4 \\
\hline 6 & $6.63-6.66 \mathrm{~m}$ & 112.4 \\
\hline 1 ' & $2.55 \mathrm{t}(J=7.5)$ & 35.8 \\
\hline $2^{\prime}$ & $1.59 \mathrm{~m}$ & 31.3 \\
\hline $\begin{array}{l}3^{\prime}-8 \\
13^{\prime}-19\end{array}$ & $1.26 s$ & $29.3-29.7$ \\
\hline $9^{\prime}$ and 12' & $2.02 \mathrm{~m}$ & 27.2 and 26.9 \\
\hline $10^{\prime}$ and $11^{\prime}$ & $\begin{array}{l}5.35 t \\
(4.7)\end{array}$ & 129.9 and 129.9 \\
\hline $20{ }^{\prime}$ & $1.26 \mathrm{~m}$ & 31.9 \\
\hline $21^{\prime}$ & $1.26 \mathrm{~m}$ & 22.1 \\
\hline $22^{\prime}$ & $0.90 \mathrm{~m}$ & 13.9 \\
\hline
\end{tabular}

calculations, ${ }^{15}$ considering the substituent effects of the aromatic ring permitted to identify the compound as being a 3-alkenyl phenol derivative (Table 2).

The correct location of the double bond in each compound was established through the mass spectral analyses of the $\alpha$, $\beta$-bis(thiomethyl) derivatives (DMDS). The mass spectra of the DMDS derivatives showed the ion peak fragment at $\mathrm{m} / \mathrm{z} 279$ $\left(\mathrm{C}_{17} \mathrm{H}_{27} \mathrm{OS}\right)$ due to the cleavage of the bond between the carbon bearing the methylthio groups between $\mathrm{C}-10$ ' and $\mathrm{C}-11$ ' (Figure 2). So, the mass spectrum allowed to determinate the unsaturation position in the same carbon in both compounds.

The brine shrimp test (BST) was employed as a cytotoxic screening for the extracts and alkenylphenols 2 and 3. The $\mathrm{CL}_{50}$ $6259.8 \mu \mathrm{g} \mathrm{mL} \mathrm{m}^{-1}$ determinated for the hexane extract against $A$. salina could be considered as non-toxic, ${ }^{10}$ similar result found with oils without presence of alkyl/alkenyl phenols in their composition. However, the isolated inseparable alkenylphenol mixture present some toxicity $\left(\mathrm{CL}_{50} 215.4 \mu \mathrm{g} \mathrm{mL}^{-1}\right)$ in the same test.

\section{CONCLUSION}

The composition of the seeds oil from Spondias mombin is rich of unsaturated fatty acid, phytosteroids and the main triglyceride present was identified as glycerol 1,3-dioleoyl-2-linoleoyl. These findings indicate it is similar palm oil once the saturated fatty acids comprise $45 \% .{ }^{16}$ Anacardiaceae family has been the main source of alkyl phenols, which are considered a chemical marker. ${ }^{17}$ From $S$. mobim oil were isolated two alkenyl phenols identified as 1-hydroxy-3-[(Z)-10'octadecenyl]-benzene and 1-hydroxy-3-[(Z)-10'-docosenil]-benzene. Some of these compounds are considerated toxic. Although the

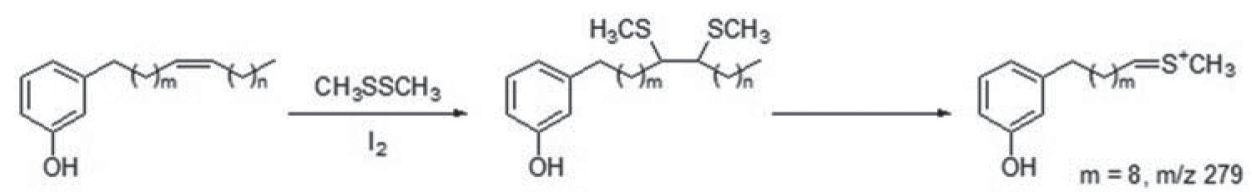

Figure 2. Synthesis of $\alpha, \beta$-bis (thiomethylic) derivatives and fragments observed in MS 
extracts showed no cytotoxicity in the BST test, compounds $\mathbf{2}$ and $\mathbf{3}$ presented low toxicity and this result indicated these vegetable oils should be better studied in order the can be used as edible.

\section{ACKNOWLEDGEMENTS}

The authors are grateful to the CNPq, CAPES and PRONEM/ FAPESB for grants and fellowships.

\section{REFERENCES}

1. Albertini, S.; do Carmo, L. F.; do Prado-Filho, L. G.; Ciênc. Tecnol. Aliment. 2007, 27, 113.

2. LaSalles, K. T. S.; Meneghetti, S. M. P.; LaSalles, W. F.; Meneghetti, M. R.; dos Santos, I. C. F.; da Silva, J. P. V.; de Carvalho, S. H. V.; Soletti, J. I.; Ind. Crops Prod. 2010, 32, 518.

3. Tiburski, J. H.; Rosenthal, A.; Deliza, R.; Godoy, R. L. O.; Pacheco, S.; Food Res. Intern. 2011, 44, 2326.

4. Pinto, W. S.; Dantas, A. C. V. L.; Fonseca, A. A. O.; Ledo, C. A. S.; Jesus, S. C.; Calafange, P. L. P., Andrade, E. M.; Pesq. Agropec. Bras. 2003, 38, 1059 .

5. Cabral, B.; Siqueira, E. M. S.; Bitencourt, M. A. O.; Lima, M. C. J. S.; Lima, A. K.; Ortmann, C. F.; Chaves, V. C.; Fernandes-Pedrosa, M. F.; Rocha, H. A. O.; Scortecci, K. C.; Reginatto, F. H.; Giordani, R. B.; Zucolotto, S. M.; Braz. J. Pharmacogn. 2011, 26, 304.
6. Corthout, J.; Pieters, L. A.; Claeys, M.; Vanden Berghe, D. A.; Vlietinck, A. J.; Phytochemistry 1991, 30, 1129; Corthout, J.; Pieters, L. A.; Claeys, M.; Vanden Berghe, D. A.; Vlietinck, A. J.; Phytochemistry 1992, 31, 1979.

7. Hamano, P. S.; Mercadante, A. Z.; J. Food Comp. Anal. 2001, 14, 335.

8. Ayoka, A. O.; Akomolafe, R. O.; Akinsomisoye, O.S.; Ukponmwan, O. E.; Afr. J. Biomed. Res. 2008, 11, 129.

9. Correia, S. J.; David, J. M.; da Silva, E. P.; David, J. P.; Lopes, L. M. X.; Guedes, M. L. S.; Quim. Nova 2008, 31, 2056.

10. David, J. P.; Silva, E. F.; Moura, D. L.; Guedes, M. L. S.; Assunção, R. J.; David, J. M.; Quim. Nova 2001, 24, 730.

11. Guillén, M. D.; Ruiz, A.; J. Sci. Food Agric. 2003, 83, 338; Carneiro, P. I. B.; Reda, S. Y.; Carneiro, E. B. B.; Ann. Magn. Reson. 2005, 4, 64.

12. Shiao, T. Y.; Shiao, M. S.; Bot. Bull. Acad. Sin. 1989, 30, 191.

13. Reda, S. Y.; Carneiro, P. I. B.; Rev. Analytica 2007, 31, 44.

14. Jie, M. S. F. L. K.; Lam, C. C.; Chem. Phys. Lipids 1995, 78, 1.

15. Breitmaier, E.; Voelter, W.; Carbon-13 NMR Spectroscopy, $3^{\text {rd }}$ ed., WCH: Weinheim, 1990

16. Dubois, V.; Breton, S.; Linder, M.; Fanni, J.; Parmentier, M.; Eur. J. Lipid Sci. Technol. 2007, 109, 710.

17. Correia, S. D. J.; David, J. P.; David, J. M.; Quim. Nova 2006, 29, 1287. 